Aus dem Anatomischen Institut der Med. Fakultät, Univ. Okayama

(Vorstand: Prof. M. SEKI).

\title{
Beobachtung der Saftlücken der Hornhaut des Frosches.
} 蛙の侍膜の液間隙の観察。

\author{
Ayame ISHII 石 井䓍 蒲.
}

[Eingegangen axe 28. Februar 1954.]

SFNFTLEBIN (1878), KRAUSE (1892), GRAWITZ (189'), SUGANUMA (1916), HUDII (1926 a, b) und viele andere untersuchten die Veränderungen der Hcrnhautspieße und anderer Zellen in der Hornhaut bei Entzündung. Über die Saftlücken und SaftkanäIchen bei solchen Zuständen ist aber sehr wenig bekannt.

Es ist eine Besonderheit der Saftlücke, daß sich in ihr die Bindcgewebszelle firdet. Jhre Form wird von den umliegenden Bindegewebsfasern und -folien beeinflußt und ist übrigens je nach ihrer Lage in der Hornhaut sehr verechieden. Im folgenden sollen das Auscehen der Saftlücken in verschiedenen Schichten der Hornhaut und ihre Veränderungen bei Beschädigungen der letzteren besprochen werden.

\section{Material und Methode.}

Man machte mit einer Nadel eine kleine Höhlung in dem centralen Teil der Hornhaut des Frosches und legte sorgfältig ein Stäbchen von Gelatinegallerte, welches $13 \%$ Silbernitrat enthält, für 20 Minuten in sie ein, spülte die Hornhaut mit einer Kochsalzlösung und exsitirpierte nach 2 Stunden den Augapfel. Man setzte die Oberfläche der Hornhaut Wasserdämpfen aus einem Topf für 2-3 Sekunden aus und strich die nun leicht getrübte Epithelschicht mit einem Haarspinsel aus. Der Augapfel wurde in 1\%iger Silbernitratlösung für 15 Minuten in Dunkel gelegt und dann in destilliertem Wasser 30 Sekunden lang gewaschen. Nach einminutigem Einlegen in 0.2\% iger Kalilaugelösung wurde der Augapfel in $0.4 \%$ ige neutrale Formalinlösung für etwa 3 Minuten gebracht, um das Silbersalz zu reduzieren. Nach Spülung in destilliertem Wasser schnitt man die Hornhaut aus. Um die Zellen in den Saftlücken darzustellen, bleichte man die geschwärzte Hornhaut mit Kaliumpermanganat und Oxalsäure-Natriumsulfit insoweit, daß die Saftlücken nicht ganz unbemerkbar werden, und färbte die Hornhaut mit $0.1 \%$ iger Toluidinblaulösung.

Andererseits machte man, wie erwähnt, eine Höhlung in dem centralen Teil der Hornhaut, spülte diese 20 Minuten lang mit fließendem Leitungswasser und exstirpierte den Augapfel nach 15 Stunden. Die 
Silberfärbung der Hornhaut und die Färbung der Zellen in den Saftlücken erfolgten wie oben.

Zur Kontrolle befreite man die unverletzte Hornhaut in der oben erwähnten Weise von dem epithelialen Überzug und färbte sie nach der Formalinfixierung mit Toluidinblau. Im übrigen fixierte man die Hornhaut mit Formalin, verfertigte $30 /$ dicke Gefrierschnitle und färbte diese mit Toluidinblau.

\section{Befunde.}

A. Veränderungen der Saftlücken in der tiefsten Schicht der Hornhaut nach der Verletzung und Silbernitratätzung des centralen Teils der Hornhaut.

In der unmittelbaren Umgebung der Ätzung wird die Substanz zwischen den Saftlücken, d. h. die Grundsubstanz, nicht mit Silber geschwärzt, so daß die Saftlücken nicht bemerkt werden (Abb. 1). In der

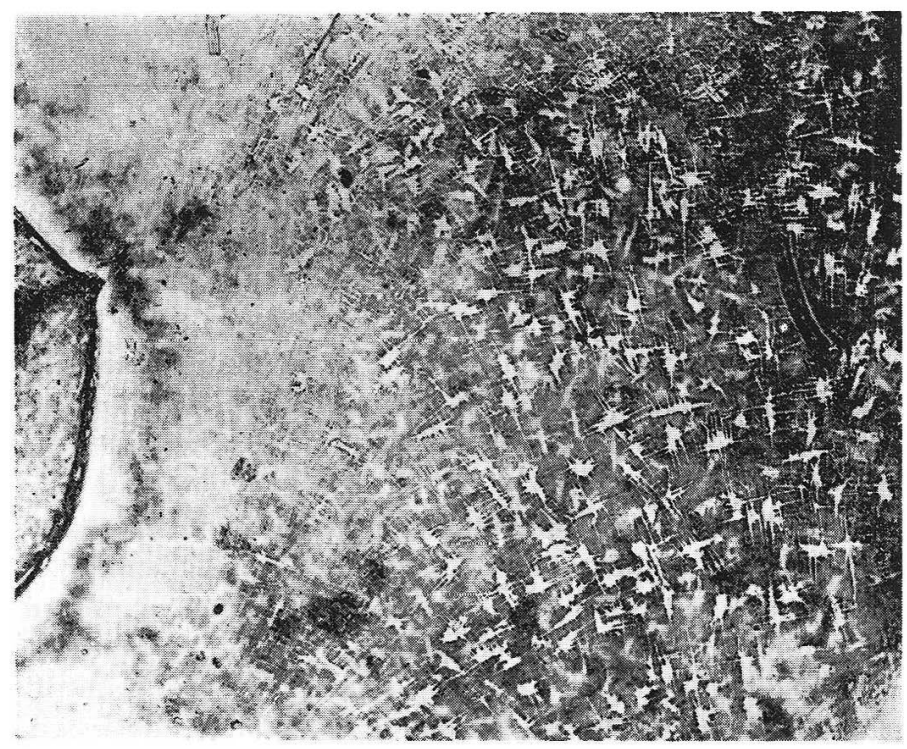

Abb. 1. Verletzung und Ätzung des centralen Teils der Hornhaut des Frosches mit Silbernitrat. Die Saftlücken und -kanälchen sind durch Silberschwärzung dargestellt. $70 \times$.

darauf folgenden Zone, in welcher die Saftliicken bemerkbar sind, ist ihr Raum etwas einengt (Abb. 2). Nach außen wird die Grurdsubstanz besser geschwärzt, daher treten die Saftkanälchen, die die benachbarten Saftlïcken verbinden, deutlich auf (Abb. 4). Die Saftkanälchen kreuzen 


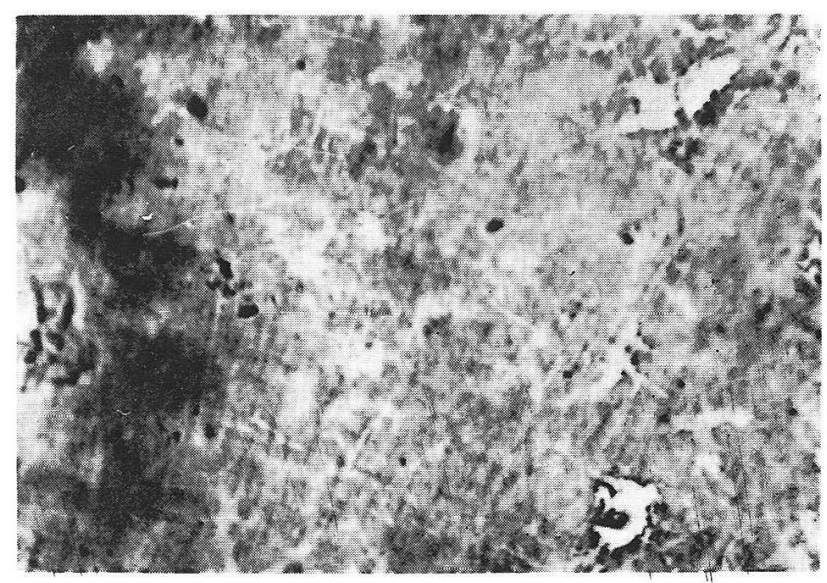

Abb. 2. Aus der Nähe der geätzten Stelle in Abb. 1. 280x.

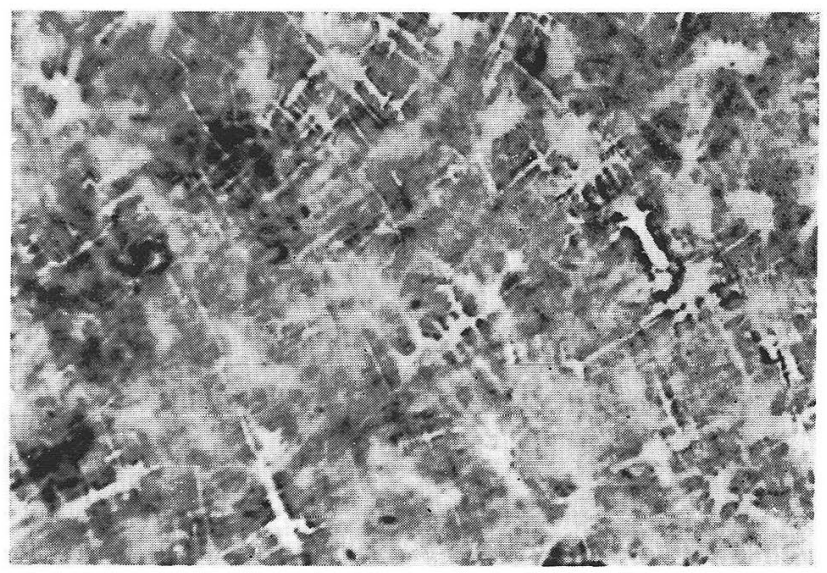

Abb. 3. Aus der von der geätzten Stelle in Abb. 1. etwas entfernten Zone. $280 \times$.

sich meist senkrecht. Die Kreuzpunkte erweitern sich ein wenig.

\section{B. Veränderungen der Saftlücken in der itiefsten Schicht der Hornhaut nach der Verletzung und Wasserspülung des centralen Teils der Hornhaut.}

Um die verletzte Stelle ist die Grundsubstanz der Hornhaut, wie bei der Ätzung mit dem Silbernitrat, nicht mit Silber geschwärzt (Abb. 5). In der nächsten Zone sind die Saftlücken zwar bemerkbar, aber abgerundet und durchschnittlich etwas enger als bei der Ätzung mit 


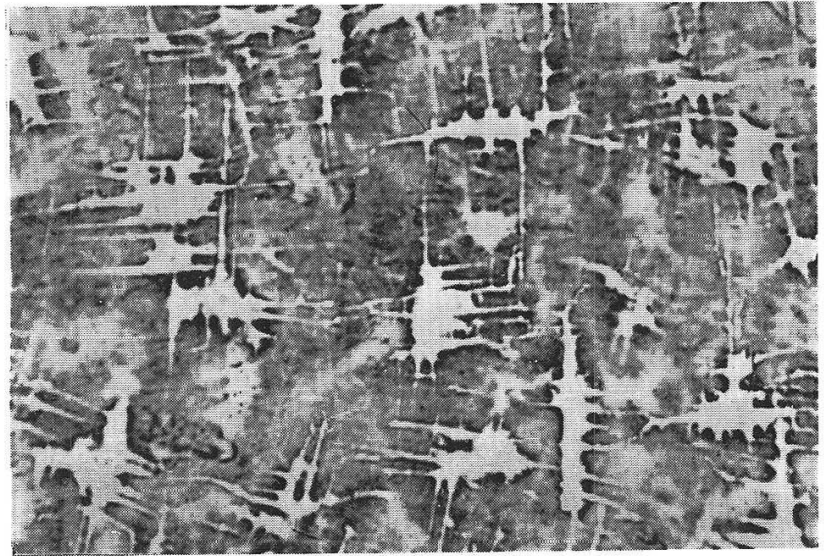

Abb. 4. Aus dem von der geätzten Stelle in Abb. 1 weit entfernten Randteil der Hornhaut. $280 \times$.

Silbernitrat. Die Saftkanälchen, die die benachbarten Saftlücken verbinden, sind zum Teil verschwunden, und die Reste bleiben in Form der kurzen Fortsätze der Saftlücken zurück (Abb. 5 u. 6). In dem von der Verletzungsstelle weit entfernten Teil der Hornhaut schwärzt sich die Grundsubstanz gut, und die Saftlücken und Saftkanälchen werden ganz klar dargestellt.

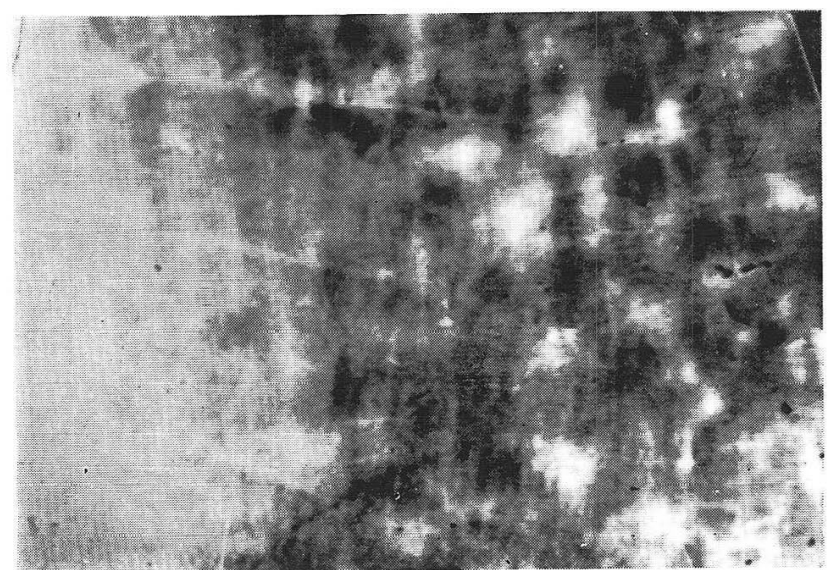

Abb. 5. Waschen der Stichwunde an dem centralen Teil der Hornhaut mit fließendem Wasser. Silberschwärzung. Aus der Nähe der Wunde. $280 \times$. 


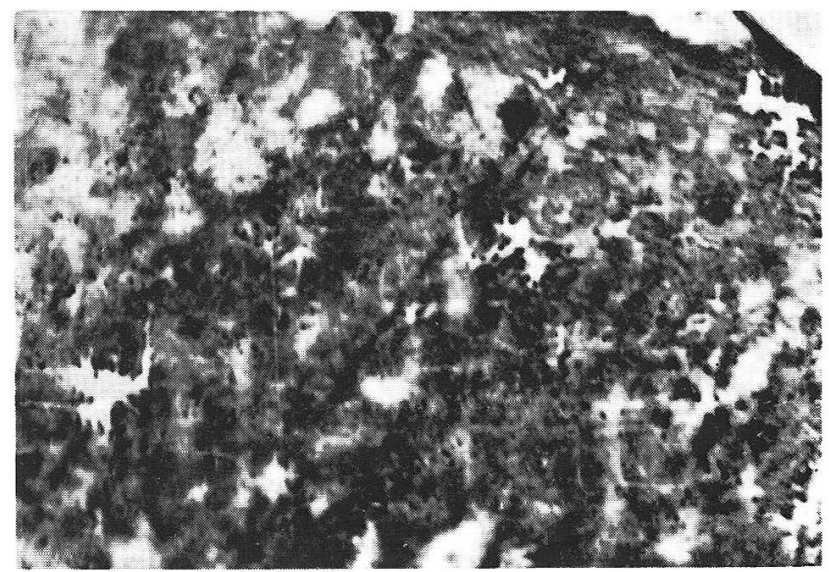

Abb. 6. Aus der von der verletzten Stelle in Abb. 5 etwas entfernten Zone. $280 \times$.

\section{Beobachtung der Zellen in den Saftlücken.}

Wenn man die mit Silber geschwärzte Hornhaut mäßig bleicht, wird die Kontur der Saftlücken zwar unschärfer, man kann aber ganze Schichten der Hornhaut gut beobachten. Man ersieht, daß in der obersten und tiefsten Schicht der Substantia propria der Hornhaut die Saftlücken sich flach verbreiten, während sie in den mittleren Schichten schmal und lang sind. Wenn man die so gebleichte Hornhaut mit Tolıidinblau färbt, treten die Zellkerne in den Saftlücken blau gefärbt hervor. Die Kerne in der obersten und tiefsten Schicht sind flach und rundlich bis ellipsoid und färben sich immer schwach, weil sie sehr dünn sind (Abb. 7). In den mittleren Schichten sind sie stäbchen-,

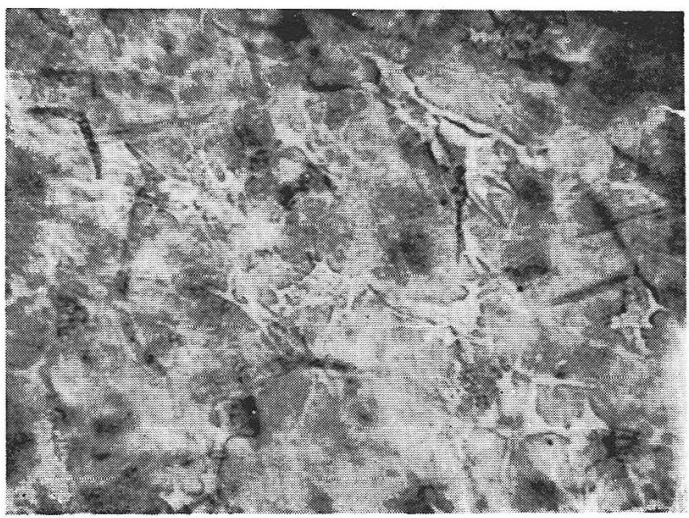

Abb. 7. Saftlücken und Zellkerne in der tiefsten Schicht der Substantia propria der Hornhaut des Frosches. Silberschwärzung, halb gebleicht und Färbung mit Toluidinblau. $250 \times$. 
spindel- oder spießförmig und stärker färbbar (Abb. 8).

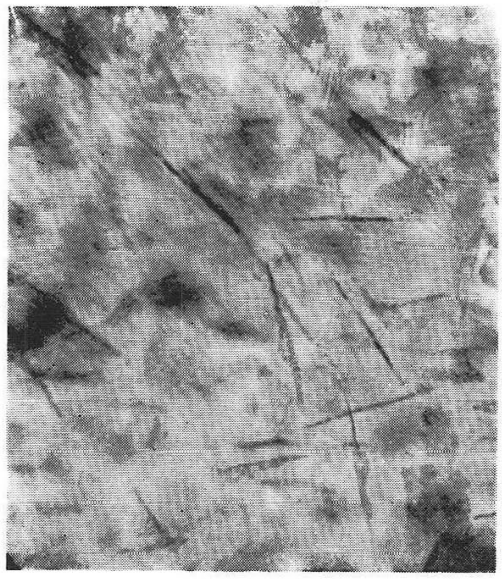

Abb. 8. Aus der mittleren Schicht der Substantia propria des Materials wie in A bb. 7. $250 \times$.

$\mathrm{Zu}$ bemerken ist, daß nach der zur Entfernung des Epithels vorgenommenen Bedampfung der Hornhaut das Cytoplasma der Bindegewebszellen körnigblasig wird, unabhängig davon, ob die Hornhaut zuvor normal oder beschädigt ist. In den Gefrierschnitten der Hornhaut ohne Bedampfung bietet das Cytoplasma keine solche körnig-blasige Struktur. Diese Struktur muß also als ein durch die Hitzwirkung hervorgerufenes Kunstprodukt angesehen werden.

Ich untersuchte auf das sorgfältigste die Umgebung der verletzten bzw. geätzten Stelle der Hornhaut und sah nach, ob die Zellen in den Saftlücken sich von der Wand abtrennen und sich abrunden. Diese Frage war aber schwer zu entscheiden, da die Zellen zu dünn sind. Daß die Zellen mit der Abrundung und Verkleinerung der Saftlücken auch abgerundet und verkleinert werden, ist indes begreiflich. Die spindel- und spießförmigen Zellkerne in den mittleren Schichten der Hornhaut werden im allgemeinen, wie erwähnt, mit Toluidinblau gut gefärbt, aber in der Umgebung der Ätzung mit Silbernitrat werden sie mehr oder weniger schlechter färbtar.

\section{Zusammenfassung.}

Fis wurde der centrale Teil der Hornhaut des Erosches nach der Verletzung mit Silbernitrat 20 Minuten lang geätzt oder mit fliessendem Wasser 20 Minuten lang gewaschen. Der Augapfel wurde im ersteren Fall nach 2 Stunden und im letzteren Fall nach 15 Stunden herausgenommen. Nach der Entfernung des Epithels schwärzte man die Grundsubstanz zwischen den Saftlücken mit Silbernitrat, eventuell färbte man auch die Kerne der Bindegewebszellen mit Toluidinblau und beobachtete die Saftkanälchen und Zellen.

1. In der obersten und tiefsten Schichte der Substantia propria der Hornhaut sind die Saftlücken, in welchen Bindegewebszellen existieren, abgeflacht. Von ihnen gehen zahlreiche Saftkanälchen aus. Die Saftkanälchen aus einer Saftlücke anastomosieren mit denjenigen aus den benachbarten Saftlücken. Die Saftkanälchen verbinden sich meist mit 
einigen, zu ihnen senkrechten Saftkanälchen. Die Verbindungspunkte der Saftkanälchen sind etwas verbreitet. In den mittleren Schichten der Substantia propria sind die Saftlücken und Zellen stäbchen-, spindeloder spießförmig gestaltet.

2. Unmittelbar um die verletzte Stelle der Hornhaut wird z. B. in der tieftsen Schicht der Substantia propria die Grundsubstanz zwischen den Saftlücken mit dem Silber nicht geschwärzt, weil wahrscheinlich Schutzkolloide infolge der Aufquellung der Grundsubstanz entstanden und die Entwicklung der metallischen Silberteilchen und Ablagerung hindern, so daß also die Saftlücken nicht sichtbar gemacht werden. In der nächsten Umgebung sind die Saftlücken mehr oder weniger rundlich und einengt geworden. Die Saftkanälchen verschwinden auch vielerorts. Die Veränderungen der Form der Zellen in den Saftlücken sind wegen ihrer Dünne nicht klar festzustellen.

\section{內 容自 抄。}

蛙の角朕の中心部に孔をあけ，硝酸銀を含むゲラチンの棒で20分間腐玲 して2 時間後飞，また針で傷つけ，流れる水道水と20分間当てて15時間後 に, 夫々眼球を摘出し，上皮を除き，液間隙の間の基質を銀染し，時には な括トルイヂン青で染め, 液間吵と細胞を観察した。角膜固有層の最上層 と最下層では細胞の占居する液間吵は扁平で広く，それょり多くの液小管 が出で，液小管は隣在の液間隙からのものと吻合し，また多くは直角の方 问の液小管で連絡し，その連絡部はやや太くなっている。しかるに固有層 の中層では液間隙と細胞は杆形，紡錘形，槍形等である。

角膜損傷部のすぐ周りで固有層の最下層を見ると，多分物質が膨化し保 護膠質が生じたため，ここには銀精子の発達と沈着が起らず，基質が黑く ならないから，液間隙は認められない，損傷部を少し遠ざかったところで は液間陌がやや丸味を带び，小さくなり，多くの液小管が消兄ている．液 間隙にある細胞の外形の変化は細胞が薄いためょく分らない。しかし液間 隙の形の変化伴って変化していることは確かである.

\section{Literatur.}

Grawitz, P.: Über die Entzündung der Hornhaut. Virchows Arch. 144 (1896). - Hudii, K. : Über den Mechanismus der Entstehung der entzündlichen Hornhautspieße. (Jap.) Acta Soc. ophtalm. jap. 30 (1926 a). - Experimentelle Uutersuchungen über sog. Schlummerzellen der Hornhaut. Okayama I. Z. 437 (1926 b). - Krause, A.: Über Entwicklung, Bau und pathologiche Veränderungen des Hornhantgewebes. Virchows Arch. 128 (1892). - Senftleben : Beiträge zur Lehre von der Entzündung und den dadbei auftretenden corpus- 
culären Elementen. Virchows Arch. 72 (1878). - Suganuma, S.: Über die Anwendung der vitalen Färbung zum Studium der Entzündung der Hornhaut (Über Entstehung der Hornhautspieße). (Jap.) Acta Soc. ophthalm. jap. 20 (1916). - Pathologie des Auges. Bd. 1. Tokyo 1932. 